\title{
GÊNERO E SEXUALIDADE: ONDE ESTÃO ESSAS QUESTÕES NO CURRÍCULO DA LICENCIATURA EM GEOGRAFIA DA UFRGS?
}

\author{
Gender and Sexuality: Where are these issues in the grace of rescue in UFRGS Geography?
}

\author{
Cláudia Maliszewski Escouto * \\ Ivaine Maria Tonini ** \\ *Mestranda (POSGea/UFRGS) - claudia.m.escouto@gmail.com \\ ** Professora Faced/UFRGS - ivaine@terra.com.br
}

Recebido em 15/08/2018. Aceito para publicação em 03/09/2018.

Versão online publicada em 20/11/2018 (http://seer.ufrgs.br/paraonde)

\begin{abstract}
Resumo: Este trabalho objetiva uma breve discussão acerca das questões de gênero e sexualidade, com a intenção de mostrar as ausências destas temáticas no currículo do curso de Licenciatura em Geografia da Universidade Federal do Rio Grande do Sul (UFRGS) e quais suas possíveis consequências. Atualmente, falar sobre esses temas nas escolas passou a ser uma demanda social, já que nunca se falou tanto sobre a diversidade sexual e de gênero como se tem falado hoje em dia. A análise é feita por uma moldura teórica tanto por autores da linha de Ensino de Geografia e também dos Estudos de Gênero, no viés pós-estruturalista, onde os conceitos de gênero, sexualidade, currículo e ensino são tensionados.
\end{abstract}

Palavras-chave: Ensino de Geografia; Gênero; Currículo..

\begin{abstract}
This paper aims at a brief discussion about the issues of gender and sexuality, with the intention of showing the absences of these themes in the curriculum of the Degree in Geography of Universidade Federal do Rio Grande do Sul (UFRGS) and what its possible consequences. Nowadays, talking about these themes in schools has become a social demand, since there has never been much talk about sexual and gender diversity as it has been spoken today. The analysis is done by a theoretical framework both by authors of the Geography Teaching line and also by Gender Studies, in the poststructuralist bias, where the concepts of gender, sexuality, curriculum and teaching are stressed.
\end{abstract}

Key-words: Geography Teaching Gender; Curriculum.

\section{Para começo de conversa}

Hoje a discussão acerca de questões que envolvem gênero e sexualidade está muito em voga. É possível de certa forma dizer que é um dos principais assuntos da atualidade visto o número de debates que se vê na mídia e é claro nos centros de ensino. Tanto em universidades quanto em escolas, falar sobre gênero ou sexualidade é dos assuntos mais falados entre os alunos. 0 que a nosso ver é algo extremamente positivo. Entretanto o auge desses temas tem dois lados.

Se por um lado essa discussão trouxe a tona o debate, por outro lado também mostra o quanto os cursos de formação de professores ainda estão muito distantes de abarcarem essas demandas em seus currículos. Aqui neste caso referímo-nos com mais propriedade a respeito do currículo do curso de Licenciatura em Geografia da UFRGS (Universidade Federal do Rio Grande do Sul).

É importante dizer que embora os currículos tenham uma preocupação quanto às diversidades, esse termo é muito amplo, e cabe dentro dele uma infinidade de agendas que merecem cada uma ser tratada com mais atenção. Embora seja muito fácil inserir o assunto gênero nas aulas de Geografia, ele não é firmado nos seus currículos, ainda mais agora com a exclusão das expressões gênero e sexualidade da terceira versão da Base Nacional Comum Curricular. Quando se fala em desigualdade sexual (homens com salários ainda maiores que os das mulheres) isso é uma questão de gênero. $\mathrm{Ou}$ mesmo o feminicídio, e a violência contra mulheres de forma geral, também é falar sobre gênero. 0 
problema é que a palavra gênero anda sendo tão difundida de maneiras tão tortuosas, que parece ter sido mistificada como algo ruim. Em grande parte isso se deve a discursos extremos vindos de machistas e conservadores autodeclarados. Mas o que importa aqui é a reflexão sobre qual o motivo de haver a ausência dessas questões nos currículos de forma geral? Quem se preocupa com a inserção desses temas no currículo da Geografia? Quem são as pessoas engajadas que querem essa mudança e sentem que ela é urgente e necessária?

Embora não tehamos respostas para essas perguntas, acreditamos que esses questionamentos precisam ser feitos durante todo o curso que irá formar um(a) professor(a). Visto que hoje não há disciplinas específicas para a abordagem das questões de gênero e sexualidade, a reflexão é bem vinda. Isso faz com que a situação já bastante complicada devido atantas ausências, seja de certa forma amenizada através da discussão e reflexão.

\section{Pensando sobre o assunto}

Falar de gênero hoje é comum, principalmente se for negativamente. Esse parece o assunto da vez. Tanto que até movimentos contrários a uma suposta "ideologia de gênero" tem surgido aos montes. Mas o que isso tudo quer dizer? Poderíamos dizer que a culpa dessa "perseguição" as temáticas de gênero e sexualidade é fruto de uma onda conservadora que infelizmente tem crescido cada vez mais não apenas no Brasil, mas no mundo todo pelo o que se tem visto. No entanto, a questão é bem mais profunda.

Num primeiro momento é preciso deixar claro que trata-se de uma questão cultural. Cultural no sentido de que vivemos em uma cultura sexista, homofóbica, racista e com tantos outros preconceitos que são ensinados a todos nós. Sim, são ensinados. Aqui a máxima dita pela Simone de Beauvoir "ninguém nasce mulher, torna-se mulher" é facilmente adequada para "ninguém nasce machista, torna-se machista", ou ainda "ninguém nasce homofóbico, torna-se homofóbico".

Diante disso é preciso compreender que esses preconceitos fazem parte da nossa cultura e nos cercam o tempo todo. E é um exercício enorme primeiro de se reconhecer como sujeito que carrega essas características. 0 segundo passo é tentar reeducar-se para não continuar cometendo os mesmos erros e assim por diante. É um processo longo. Tão longo que pode nem acontecer. E muitas vezes nem acontece. E por que? Porque não se discute em aula. Porque ignoram essas questões. Porque finge-se que elas não existem, que não fazem parte da aula. E isso é uma deficiência grave do currículo.

Uma deficiência do currículo, pois assim como o currículo é um território de disputas, essa agenda tem sido alvo constante na arena da sociedade e está frequentemente sendo atacada e impactada por retrocessos. Retrocessos que sem dúvida trarão sérias consequências a médio e longo prazo.

Como Paraiso (2017) coloca "um currículo é um território de ensinar e de aprender por excelência", ou seja, ele sempre ensina algo, e nós sempre aprendemos alguma coisa. Então, isso de certa forma quer dizer que, se as questões de gênero e sexualidade não estão no currículo, isso significa que nos é ensinado no mínimo que elas não devem estar lá. E por consequência aprendemos que se não devem é porquê não precisamos aprender. Esse pensamento simplista, é também reflexo do preconceito.

\section{A situação hoje}

Hoje não é nenhuma novidade os altos índices de violência sofridos por LGBTs (Lésbicas, Gays, Travestis, Transexuais e Transgeneros) e também pelas mulheres. É com frequências que notícias sobre estupros coletivos e morte de pessoas trans chegam até nós. E será que ninguém se pergunta o motivo dessas mortes? Talvez não! Talvez passe despercebido pela maioria das pessoas e o motivo é a falta de discussão, falta de provocar o debate, de expor essas realidades e questionar seus motivos.

Pensando em dados e números, como mostra a figura a seguir, o Brasil é o país que mais mata população trans no mundo. Ou seja, tira-se o título de Brasil: país da diversidade, e entra em cena o título de Brasil: pais da intolerância.

ParaOnde!?, Porto Alegre, v.10, n.2, p.186-190, 2018. Edição Especial com artigos publicados originalmente na ENANPEGE http://seer.ufrgs.br/paraonde 


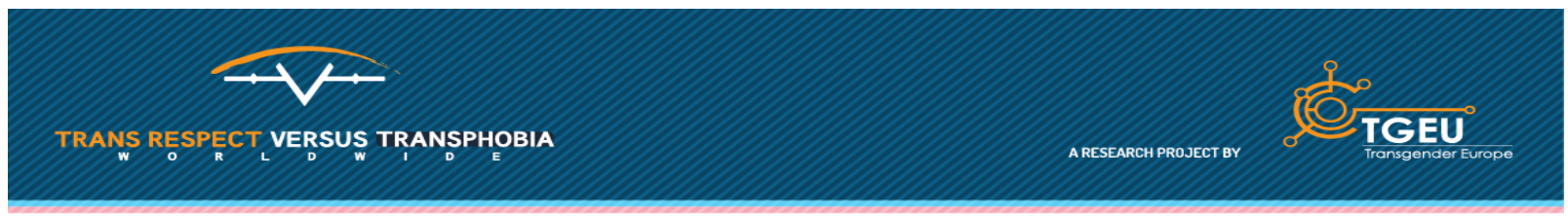

TMM TRANSGENDER DAY OF VISIBILITY 2016 UPDATE

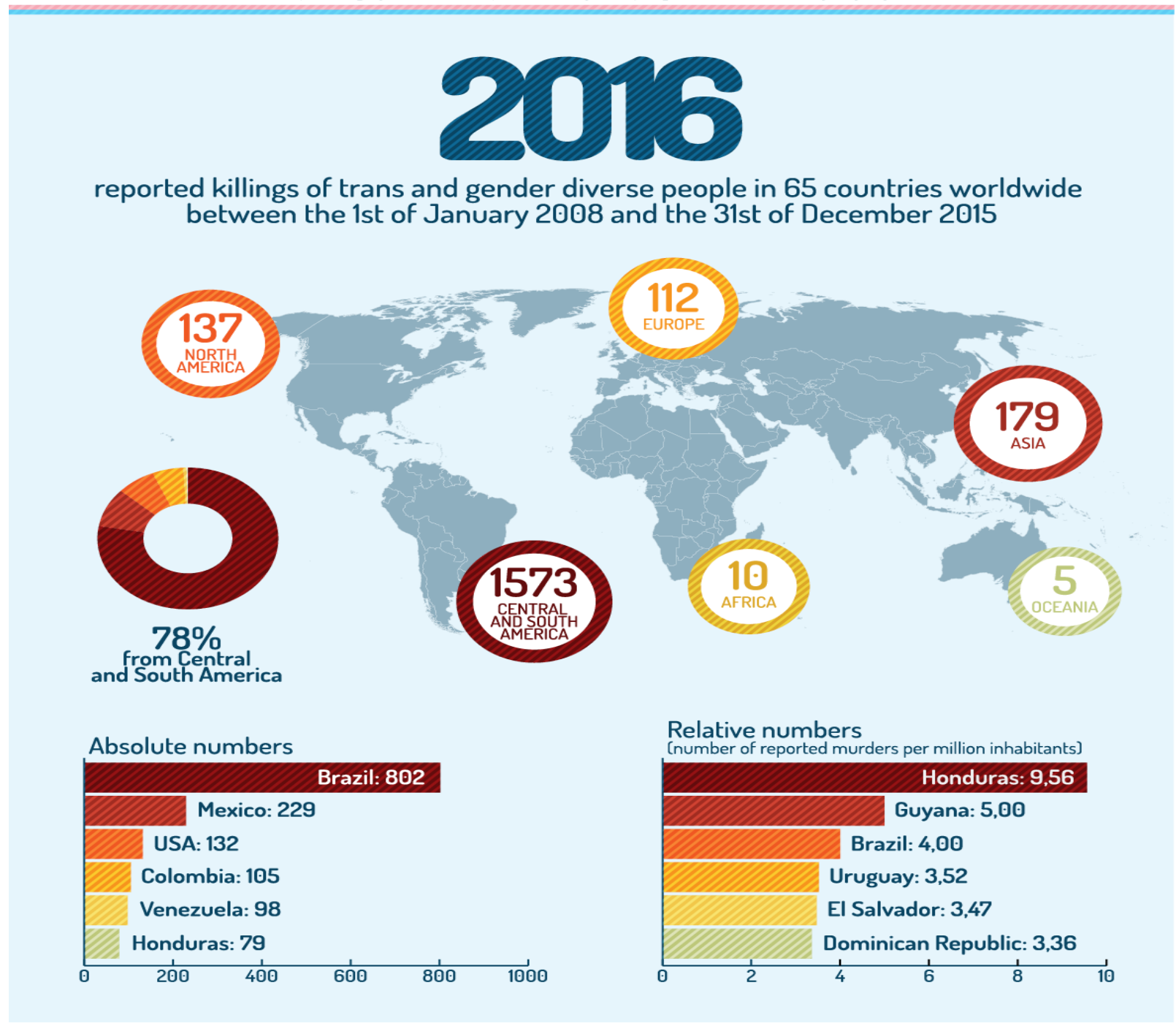

\section{Relatório do número de assassinatos de pessoas trans.}

Esse mapa ilustra uma realidade que a sociedade parece não ver. E se vê, parece que não se importa. Só que enquanto não se importam, pessoas estão sendo assassinadas, e isso é bem grave. Grave pois não vivemos em um país que tenha leis de extermínio contra a população LGBT, grave porquê em princípio vivemos em uma democracia e numa sociedade que diz presar pelo respeito as diferenças. Mas sabemos que a prática é bem diferente da teoria.

Estamos vivendo tempos de extrema intolerância onde não precisamos de leis para matar pessoas trans, elas são mortas motivadas pela intolerância e falta de informação. Acreditamos que a homofobia, a transfobia, o machismo e tantos outros preconceitos são causados principalmente pela falta de informação. E não apenas pela falta de informação de não saber o que é uma pessoa trans. E sim pela falta de informação sobre o pensamento de que é preciso respeitar e conviver com quem é diferente de nós. 


\section{E onde fica o currículo}

Você pode (e tomara que esteja) questionando ou perguntando-se: Como mudar essa realidade? A primeira resposta e bem ampla é: através da educação. Compartilhamos do pensamento de Kaercher $(2014$, p. 30) de que todo professor é um crente. E por isso, acreditar em mudanças é preciso! Mas essa mudança, precisa começar a ser coloca em prática na base, na base da formação de professores. Ou seja, começa pelo currículo.

As ausências dessas questões no currículo de um curso que irá formar professores é bem preocupante. Isso mostra o quanto o currículo é despreocupado com a diversidade e o quanto permite que os futuros professores também o sejam.

É ai que entra a educação. Professores que em suas salas de aula conseguem e permitem o debate acerca dessas questões, que buscam desconstruir pensamentos carregados de preconceito são fundamentais para que haja uma mudança significativa na formação de cidadãos. Mas como desejar que os professores e as professoras da escola básica façam isso se sua formação docente não lhes ofereceu suporte para isso?

Trata-se de algo complexo. Mas não é por ser complexo que deve ser deixado de lado. Quando buscamos conversar com professores em formação (e já formados) a respeito de questões envolvendo gênero e sexualidade, a resposta era quase unânime: não falamos sobre gênero e sexualidade em nossas aulas porque não tivemos preparo para isso! E de fato não tiveram. Ao longo dos anos do curso de graduação, a ausência desssas questões no currículo, dá margem para que o assunto seja facultativo. Ou seja, depende da vontade ou não dos professores universitários tratarem ou não essas temáticas em suas aulas. Isso mostra que dessa forma a mudança, uma escola mais acolhedora com professores e professoras que se encontrem preparados para lidar com as diversidades é quase uma utopia. Pois faz com os docentes sintam-se despreparados para lidar com questões relacionadas a diversidade tanto sexual quanto de gênero. E certamente essas questões irão surgir em suas salas de aula, pois como Louro (2004, p. 85), corrobora:

Essa presença da sexualidade independe da intenção manifesta ou dos discursos explícitos, da existência ou não de uma disciplina de "educação sexual", da inclusão ou não desses assuntos nos regimentos escolares. A sexualidade está na escola porque ela faz parte dos sujeitos, ela não é algo que possa ser desligado ou algo do qual alguém possa se "despir".

Como a autora deixa claro, essas questões tanto de sexualidade quanto de gênero estão na escola porque fazem parte dos sujeitos. E os sujeitos tem sexo e tem gênero.Ou seja, mostra o quanto é impossível fugir de discussões que envolvam esses temas.

0 currículo na universidade precisa usar o fato de ainda estar sendo pouco atacado a seu favor. Pouco atacado porque como temos visto, o da escola básica está sendo bastante atacado pelo conservadorismo que quer ver bem longe das escolas as questões ligadas a gênero e sexualidade. Como exemplos disso tivemos primeiro a não inclusão das palavras gênero e sexualidade dos Planos Nacionais de Educação, e agora mais recente a retirada dessas mesmas expressões da última versão do texto apresentado da Base Nacional Comum Curricular. Diante disso, as universidades juntamente com seus cursos de formação de professores devam se mobilizar antes que nada reste a fazer.

Com a sua possível autonomia, os cursos de licenciatura precisam se conscientizar da importância da discussão dessas temáticas na escola para que dessa forma consiga oferecer uma formação que respeite a diversidade e preze pela cidadania. E não uma formação que permita que o preconceito continue acontecendo das mais variadas formas possíveis.

Como destaca Paraiso (2017):"Um currículo é um artefato que ensina porque uma de suas funções é transmitir conteúdos, saberes, conhecimentos, conceitos, habilidades, competências, culturas, valores, condutas, modos de ser, estar e viver já pensados e aceitos."

A partir desse pensamento da autora, é possível entender o quanto um currículo pode ensinar, e pode ensinar até mesmo a ser intolerante para com a diversidade. Pois discutir gênero é abordar um 
conjunto de problemas que estão na estrutura do Brasil, como a violência contra a mulher, a cultura do estupro, a desigualdade salarial entre homens e mulheres, os assassinatos de pessoas trans (lembrando novamente que somos o país que mais mata essa população no mundo). Esses são alguns problemas que tem que ser reconhecidos e enfrentados para acabar com a cultura machista, racista e homofóbica enraizada que existe nesse país.

\section{Algumas Inconclusões}

Como já foi dito, gênero e sexualidade não se fazem presentes no currículo do curso de Licenciatura em Geografia da UFRGS. Não existe nem uma disciplina específica. 0 que faz com que fique a critério de cada professor ou professora mencionar tais assuntos em suas aulas, o que é bem difícil de acontecer. Quando são mencionados, são em conteúdos diluídos em outros, muitas vezes, como exemplos. A ausência total de disciplina especifica sobre questões de gênero e sexualidade, é algo que precisa ser pensando nos currículos com urgência, sobretudo no currículo responsável pela formação de professores.

Cada vez mais retrocessos vêm acontecendo nos documentos que devem servir como norteadores para os currículos da escola básica. Tais como a Base Nacional Comum Curricular e o Plano Nacional de Educação, nos quais as expressões "gênero" e "sexualidade" já foram retiradas. Já que a educação básica vem perdendo campo nessas temáticas, é preciso que a educação superior se mobilize para reverter esse triste quadro de intolerância e preconceito que vem sendo aumentado.

Não se pode mais esperar sem fazer nada. É preciso agir. E inserir essas agendas nos currículos de formação de professores é lutar por uma sociedade mais cidadã e tolerante para com as diversidades!

\section{Referências}

KAERCHER, Nestor André. Se a geografia escolar é um pastel de vento o gato come a geografia crítica. Porto Alegre: Evangraf, 2014. 248 p.

LOURO, Guacira Lopes. Gênero, sexualidade e educação: Uma perspectiva pós-moderna. Petrópolis: Vozes, 2014. $184 \mathrm{p}$.

SEFFNER, Fernando . Tem nexo não falar sobre sexo na escola? TEXTUAL (PORTO ALEGRE), v. 1, p. 22-29, 2017.

PARAISO, Marlucy Alves. Currículo e relações de gênero: entre o que se ensina e o que se pode aprender. Revista Linhas. Florianópolis, v. 17, n. 33, p. 206-237, jan./abr. 2016.

TGEU, Transgender Europe. Transgender Day of Visibility 2016 - Trans Murder Monitoring Update. Disponível em: < http://tgeu.org/transgender-day-of-visibility-2016-trans-murder-monitoringupdate/> . Acesso em: 20 maio 2017. 